\title{
Discurso, derecho y poder: El discurso jurídico entre la dominación y la emancipación.
}

\section{Entrevista a Mauro Benente}

Abogado por la Universidad de Buenos Aires (UBA). Doctorando en Derecho (UBA). Becario doctoral del Consejo Nacional de Investigaciones Científicas y Técnicas con un proyecto titulado "El rol del derecho en el discurso biopolítico".

Por:

Jose Daniel Fonseca-Sandoval

Universidad ICESI

jfonsandoval@hotmail.com

Entrevista recibida el 02/05/2018 y aprobado el 16/07/2018

Cómo citar este artículo:

Fonseca Sandoval, J. (2018). Discurso, derecho y poder: el discurso jurídico entre la dominación y la emancipación. Trans-Pasando Fronteras, (12). 


\section{- En Trans-pasando Fronteras creemos fundamental el lugar enunciativo; es decir, la posición y el espacio desde el cual se plantean las ideas. En ese sentido, ¿cuál es su trayec- toria y experiencia a nivel académico y profesional?}

Me parece interesante situar el lugar de enunciación, que en mi caso me esfuerzo para que sea crítico y de izquierdas. Si bien no me parece tan sencillo reconstruir el recorrido que da forma a los lugares de enunciación, diría que mi (intento de) mirada crítica y de izquierdas fue construida más a pesar que gracias a mi formación curricular. En la carrera de abogacía y luego de doctorado en la Facultad de Derecho de la Universidad de Buenos Aires, recibí una formación más bien conservadora, con algunos tintes liberales.Creo que los autores que más leí y leo son Karl Marx y Michel Foucault, y a ninguno de los dos los abordé en mi formación de grado y posgrado. Antes de terminar abogacía inicié mis estudios en la carrera de Ciencia Política, y creo que ello me permitió tener una mirada menos inconsistente y menos conservadora de los asuntos jurídico-políticos, pero igualmente sospecho que este lugar de enunciación de izquierdas no se explica por mi formación curricular. En la actualidad hago del trabajo académico mi profesión, pero antes trabajé como asesor legislativo y como empleado del Poder Judicial.En el Poder Judicial tenía una muy buena remuneración, un horario de trabajo relativamente reducido, y un período de vacaciones bastante extenso.

Ahora soy menos marxista, pero por ese entonces sentía que con mi trabajo estaba confirmando que el derecho era una herramienta de clase, por lo que ni bien pude renuncié, para trabajar más horas y por menos dinero. En general en las trayectorias profesionales se enuncian los lugares de trabajo, pero en algunos casos me parece importante subrayar las razones por las cuales, parafraseando a "Bartleby" de Herman Melville, hemos preferido no hacer ciertas cosas, 
no trabajar en ciertos espacios. De mi trayectoria académica quisiera remarcar tres elementos. En primer lugar, mi paso por la cátedra de Roberto Gargarella cuando todavía era estudiante y joven graduado, lo que me permitió mirar al derecho desde la teoría política.

En la actualidad me siento bastante lejano de su paradigma teórico -que me resulta demasiado liberal-, pero ese gesto de mirar al derecho desde la teoría ha sido muy importante para mí. En segundo lugar, completé mi doctorado con una beca del Consejo Nacional de Investigaciones Científicas y Técnicas (CONICET) y una beca más corta en el Instituto Internacional de Sociología Jurídica de Oñati. De alguna manera, mi formación doctoral tuvo un esfuerzo individual, pero bajo un paraguas estructural de un Estado que apostaba a la formación de investigadores e investigadoras, paraguas que hoy se está cerrando. Sin ese paraguas no podría haber completado mi formación doctoral, o hubiera tenido que emigrar.

En tercer lugar, quisiera destacar mi trabajo en la Universidad Nacional de José C. Paz, de reciente creación, enclavada en un territorio atravesado por múltiples opresiones y exclusiones, y a la que asisten fundamentalmente primeras generaciones de estudiantes universitarios.

Si bien en un momento tuve que renunciar a una Universidad que quedaba a 20 minutos a pie de mi casa, y la Universidad Nacional de José C. Paz queda a casi dos horas en transporte público, siento que allí la premisa crítica de construir conocimiento en vistas de la emancipación, cobra un nítido sentido: por una parte, porque los y las estudiantes cargan con una sedimentación de injusticias de distinta índole; por otra parte porque hemos dado forma a la revista Bordes, con la que buscamos que los y las intelectuales tomen intervención en los asuntos de discusión pública. 
- Al igual que el pensamiento filosófico de nuestra-américa, el conocimiento jurídico ha estado influido por las teorías y formas institucionales europeas y estadounidenses. ¿Los currículos en derecho siguen esta misma línea o hay una proliferación de teorías propias e idiosincráticas?

Una de las dimensiones de las prácticas coloniales fue, y es, la coIonialidad del saber. Los currículos de derecho no son ajenos a esta colonialidad del saber: los ejes que estructuran los ordenamientos legales, y las categorías con las que los analizamos, tienen su origen en la modernidad europea. Por su parte, en la actualidad, los centros europeos y estadounidenses de producción teórica ejercen una importante influencia en Nuestra América, puesto que cuentan con notables recursos financieros y simbólicos, en contraste con la situación bastante precaria, precarizada, y en muchos casos muy incipiente, de la investigación en nuestro continente.

Creo que quienes trabajamos en Nuestra América debemos desarrollar un pensamiento situado, en el sentido de reconocer que los problemas del sur global, y de América Latina en particular, son muy distintos de los problemas de los Estados del norte global. Ahora bien, pienso que tener un pensamiento situado sobre los problemas no implica desechar de plano las herramientas teóricas y conceptuales de la tradición de la modernidad europea. Por una parte, porque es cierto que la modernidad tuvo esa dimensión de la colonialidad del saber, pero también habilita la reflexión crítica sobre esas prácticas coloniales. Por otra parte, porque podemos encontrar equivalentes funcionales -y más funcionales para Nuestra América- de esas categorías y herramientas conceptuales.

Aquello que me parece peligroso es importar e implantar marcos conceptuales de modo acrítico. Esto es delicado porque las herramientas teóricas se construyen a la luz de ciertos problemas, 
y si no las ajustamos a los problemas nuestroamericanos, corremos dos riesgos: usar categorías que terminan siendo inútiles para resolver nuestros dramas; emplear categorías que tienen implícitos problemas que no son los de nuestros pueblos, y con ello no dar luz, sepultar aún más, nuestros dramas más urgentes.

\section{- En el discurso jurídico, son vitales las herramientas de domi- nación, como el ritual y la disciplina, fundamentadas por Michel Foucault en "El orden del discurso". Desde su trabajo y labor como docente en derecho y ciencias sociales, ¿En qué consisten estas herramientas, cuales son algunos escenarios que las ejem- plifican o ilustran y que usted considere relevantes?}

En El orden del discurso, y en continuidad con lo que se lee en La arqueología del saber, Foucault plantea que en las sociedades, la producción de discurso no es libre, sino que está controlada, organizada, y distribuida de acuerdo a distintos procedimientos que tienen por objeto conjurar sus poderes y peligros, y dominar su aleatoriedad. Esto se explica porque los discursos -y el discurso jurídico no escapa a esta generalidad- no son solamente el reflejo o resultado de prácticas y correlaciones de fuerzas, sino también uno de los objetos de los cuales esas prácticas y correlaciones se quieren apropiar. Sería algo extenso enunciar las características de los controles externos, internos y vinculados al sujeto que enuncia. La disciplina es uno de los controles internos, y el ritual uno de los controles relacionados al sujeto que enuncia.

Ahora bien, para no caer en tecnicismos y ciertas complejidades que pueden traer estas categorías de análisis, diría dos cosas. Por una parte, que el discurso jurídico no es el único que está reglado y sujeto a controles; sino que todos los discursos lo están. 
Para que un discurso sea amparado bajo la sociología, o la ciencia política, también debe cumplir ciertas reglas, ciertas formalidades en la enunciación. Por ejemplo, si quiero referirme al modo en que se eligen a las autoridades políticas y no empleo conceptos como fórmula electoral, magnitud, o umbral, posiblemente mi discurso no sea tenido como propio de la disciplina de la ciencia política. Por otra parte, si bien la existencia de reglas de producción del discurso no es patrimonio del discurso científico, quizás el agravante es que ellas se aplican no solamente en el discurso académico sino también en el discurso de los tribunales, y en el discurso para acceder a los tribunales.

Es cierto que hay que democratizar el discurso académico y ello implica flexibilizar sus reglas de producción, pero más urgente es democratizar el acceso a los tribunales y para ello hay que permitir que las demandas que se presenten, que los argumentos que se brinden, puedan tramitarse judicialmente incluso cuando no cumplan con todas las formalidades que imponen las reglas del discurso judicial. En este sentido, me parece que el funcionamiento de la acción de tutela en Colombia, que no requiere de mayores formalidades en su presentación ni enunciación, es un buen ejemplo a seguir.

\section{- ¿El derecho puede ser un elemento de transformación so- cial o es netamente un instrumento de dominación?}

Es una pregunta que yo también me hago, pero no preguntándome si puede ser una herramienta de transformación, sino de emancipación o liberación. Sencillamente porque no toda transformación social es emancipadora, sino que puede ser reaccionaria o conservadora. De todas maneras, antes de contestar a la pregunta por la dimensión emancipadora del derecho, quisiera aclarar que las 
sociedades contemporáneas están atravesadas por diferentes prácticas de poder y de dominación, algunas de las cuales están reguladas y legitimadas jurídicamente, y otras se producen en los márgenes del derecho. Es decir, si bien el derecho legitima y reproduce situaciones de dominación, no todas ellas transitan por senderos jurídicos. En términos generales, creo que las normas jurídicas son una cristalización de las relaciones de fuerza de un momento determinado.

Luego esas normas pueden mantenerse cuando esas relaciones de fuerza se hayan modificado parcialmente, e incluso pueden repercutir para reorientar esas relaciones de fuerza, pero en principio el derecho tiene ese origen. Asimismo, la posterior interpretación de esas normas también es un espacio de disputa. Una disputa de argumentos, de razones, de posicionamientos ideológicos. Si bien no creo que los argumentos sean relaciones de fuerzas continuadas por otros medios, la construcción de aquello que llamamos argumento y la prevalencia de uno por sobre otros, no son dimensiones ajenas a las prácticas de poder y dominación. Si tomamos el ejemplo de la inclusión del vivir bien en la Nueva Constitución Política del Estado Plurinacional de Bolivia, no podemos olvidar el ciclo de resistencia política y social de las comunidades indígenas (re)iniciada en la década de 1990.

Y también debemos tener en cuenta que en la actualidad se trata de un concepto en disputa, que el MAS lee en una clave cercana a un Estado de Bienestar - y con ello justifica el extractivismo para luego distribuir las rentas-, mientras que buena parte de las organizaciones indígenas lee el vivir bien como un concepto que se opone a la explotación de la naturaleza, sea que luego los dividendos se redistribuyan o se giren al exterior como sucedía desde la segunda parte de los 80 y hasta el ascenso de Evo Morales. Teniendo en cuenta lo anterior, creo que las normas y las inter- 
pretaciones que emerjan de correlaciones de fuerzas emancipadoras, serán emancipadoras. Sin embargo, el derecho rara vez es emancipador porque solo excepcionalmente en nuestros pueblos las relaciones de fuerza son favorables a los sectores emancipadores. Además, un ordenamiento jurídico construido en términos generales en contextos desfavorables para los sectores populares, se erige como una valla para que emerjan esos movimientos emancipatorios. Ahora bien, me parece importante remarcar que en las últimas décadas en Nuestra América, y muy especialmente en el cono sur, buena parte de las demandas emancipadoras se realizaron con la gramática de los derechos humanos.

Movimientos sociales, e incluso organizaciones indígenas, articularon sus demandas en términos de reconocimiento, protección y defensa de los derechos humanos, derechos que las izquierdas históricamente han mirado con desconfianza. Me parece, entonces, que aquellos juristas que piensan, que pensamos, desde las izquierdas, debemos construir un discurso de izquierdas de los derechos humanos.

\section{- Teniendo en cuenta que el derecho avala y reproduce de- terminadas relaciones de poder y de dominación ¿qué papel cumplen las facultades de derecho en la consolidación de exclusiones como el racismo, el elitismo, la xenofobia?}

En primer lugar, a las condiciones de exclusión y opresión que mencionas, agregaría las motivadas en razones de clase y de géneros. En segundo lugar, creo que gran parte de la enseñanza del derecho está atravesada por lo que Duncan Kennedy denominó dimensión ideológica, y que alude a la despolitización del derecho, a la separación entre derecho y política. Si reducimos el derecho a una mera 
repetición de normas jurídicas, que en muchos casos reproducen relaciones de poder y dominación, entonces ese discurso jurídico no puede ser otra cosa que un discurso de orden. Tal como mencionaba anteriormente, el derecho es una cristalización de relaciones de fuerzas. Uno podría desarrollar una historización y politización de ese derecho, mostrar que emerge de prácticas de poder y de dominación, a la vez que las consolida y las reproduce, pero ello solamente es posible si dejamos de reducir el derecho a una mera descripción de normas y de la relación que existe entre ellas.

Es decir, el discurso jurídico no es conservador porque su objeto de estudio sea conservador, sino también porque hay una operación metodológica de delimitar el objeto de estudio solamente a esas normas, y es esta operación la que nos impiden ver que ellas pueden tener un origen injusto, reproducen un presente injusto, y no pueden más que ofrecernos un horizonte a futuro también injusto.

\section{- ¿Qué consecuencias trae que las facultades de derecho privil- egien o prioricen determinados énfasis o áreas temáticas como el derecho civil o el derecho comercial, en sus currículos?}

No creo que el problema sean los campos disciplinarios, y tampoco que sean campos tan delimitados los civiles y los comerciales - pero no sobre esto no profundizaré-. Más bien, sospecho que las dificultades se encuentran en el modo en que se abordan. Pienso que es fundamental abordar los contenidos del derecho civil y del derecho comercial, básicamente porque reproducen un elenco de relaciones sociales opresivas. Gran parte del derecho civil legitima y reproduce lo que Axel Honneth denominaría "relaciones injustificadas de reconocimiento", mientras que el derecho comercial contribuye a la reproducción de las relaciones capitalistas de pro- 
ducción e intercambio. Es decir, el problema no está en el derecho civil, o en el derecho comercial, sino en un modo muy frecuente de abordar estos asuntos, e incluso de nominarlos. Debería llamarse derecho comercial capitalista, pero ya con la denominación de derecho comercial, se universaliza y se naturaliza una modalidad de producción e intercambio. Quienes analicen la temática deberían tener presente que las categorías con la que lo hacen se corresponden con esa modalidad histórica que es el capitalismo. Para establecer una relación con la pregunta anterior, diría que el problema es que en la medida en que el derecho comercial en tanto campo disciplinario se limita a repetir las normas que regulan la producción y el intercambio capitalista, se transforma en un discurso que legitima esa modalidad de producción e intercambio.

Lo que intento sugerir es que es posible, y hasta urgente, construir algo así como un derecho civil crítico, o un derecho comercial crítico. Ahora bien, subrayando que no es un problema del campo disciplinario, al menos en Argentina no tengo ninguna expectativa que eso suceda. Por una parte, porque el campo disciplinario es reacio a todo pensamiento crítico. En segundo lugar, porque no existe una academia profesional, y quienes escriben sobre derecho civil y derecho comercial son abogados y abogadas, jueces y juezas, que se benefician con el sistema que, ese derecho que describen y aplican, reproduce.

La clave del éxito en el derecho comercial -aunque no solo en el derecho comercial- es ser abogado o abogada de una gran empresa. Esa es la clave del fracaso de un pensamiento crítico. 


\section{Número de Abogados por cada 100.000 Habitantes}

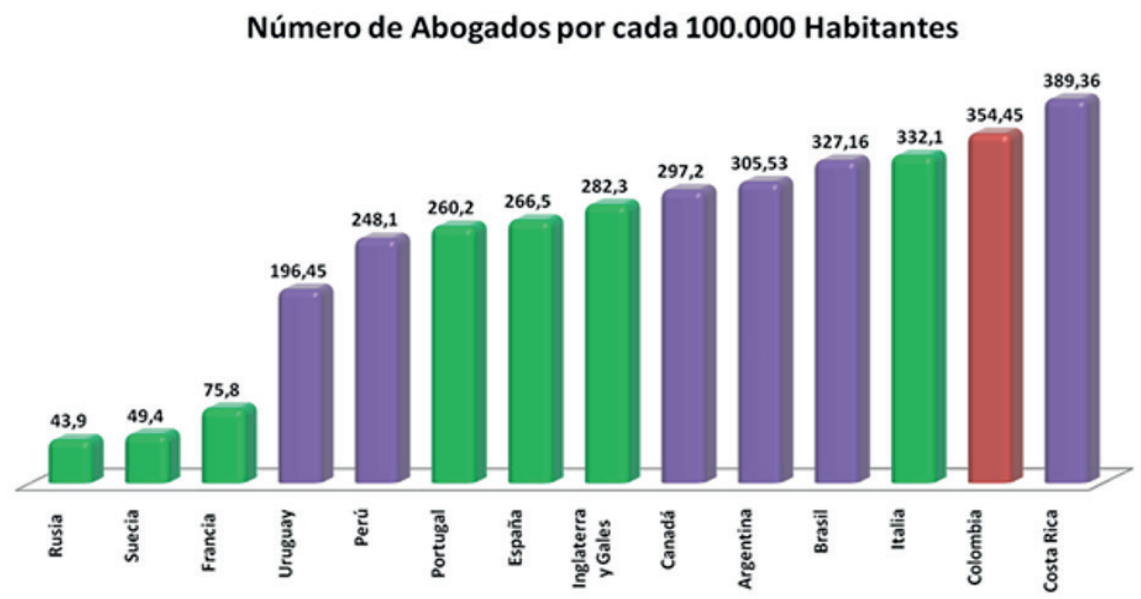

Fuente:

Comisión Europea para la eficiencia de la Jusiticia.

Nota:

- Según el reporte señalado en el cuadro, para el año 2009, Colombia, Brasil y Argentina evidenciaron cifras altas de abogados por cada 100.000 habitantes. ¿A qué se debe esta proliferación de juristas? ¿Es conveniente? ¿Cree usted que el modelo de educación jurídica tiene algo que ver en esto?

No puedo brindar respuestas consistentes a estos interrogantes. Para el caso argentino solamente puedo enunciar algunas intuiciones. Para las universidades, abrir carreras de ciencias sociales es notablemente menos costoso que instaurar carreras 
vinculadas al elenco de la física, química, medicina, ingeniería, etc. No se necesitan laboratorios, insumos onerosos, etc. Entonces, es más sencillo montar carreras de ciencias sociales. En segundo lugar, al menos en Argentina, la carrera de derecho es menos dificultosa que la de filosofía o historia.

Finalmente, y en términos generales y comparativos con otras profesiones, me parece que el trabajo de abogado/a litigante o de empleado/a o funcionario/a en el Poder Judicial es un trabajo relativamente sencillo, y bastante bien remunerado. En el caso del Poder Judicial, las condiciones de trabajo de empleados/as y funcionarios/as, y los salarios, son nítidamente mejores que las condiciones y salarios de médicos/as, maestros/as, y profesores/ as, para mencionar solamente algunos ejemplos.

\section{- El derecho ha sido fuertemente influido por la neutralidad y la objetividad como parámetros de cientificidad. Esto ha incidido en la escisión de la profesión jurídica y el compro- miso crítico y reflexivo por las transformaciones sociales del continente. ¿Cree usted que los abogados deben combi- nar su vínculo profesional del campo jurídico con actividad social de interés público y comunitario?}

Efectivamente la pretensión de cientificidad ha traído consigo la supuesta neutralidad y objetividad. En términos generales creo que la comprensión de aquello que nominamos como nuestro objeto de estudio está mediada por una pre comprensión en la cual juegan un papel fundamental los valores, la ideología, y todas las variables que cierto discurso de la objetividad pretende dejar de lado. Aun suponiendo que este universo de pre comprensión podría dejarse de lado, o controlarse, con el derecho tenemos un agravante: los componen- 
tes valorativos están dentro de los propios objetos de estudio. Los valores están en las normas jurídicas, en las sentencias, etc.

Es decir, interpretar de modo objetivo o neutral el derecho implica afirmar al mismo tiempo dos cosas: a- que ese universo de pre comprensión "contaminado" de valores y subjetividades se puede erradicar o controlar; b- que se puede "purificar" nuestro objeto de estudio, cuando en muchos casos son valores e ideologías plasmados en normas jurídicas o en sentencias. Creo que algunas tendencias que han extremado la búsqueda de objetividad, han perdido cierto compromiso crítico; o nunca lo han tenido.

Las líneas del positivismo lógico, que analizan las normas a nivel proposicional alcanzan un nivel de formalización que permite controlar -al menos parcialmente- esa pre comprensión y también purifican nuestro objeto de estudio, pero reducen tanto la dimensión de análisis que ni siquiera nos permite impugnar un sistema normativo dictado por una dictadura. Analizar las lagunas, y las contradicciones que pueden existir dentro de un sistema, nada nos dice sobre el origen democrático o dictatorial del sistema, y entonces sí creo que este tipo de formalizaciones anulan el pensamiento crítico.

De todas maneras, no me parece que la falta de compromiso crítico de abogados y abogadas litigantes se vincule con esta pretensión de objetividad. Sospecho que quienes litigan no están muy al tanto de los debates epistemológicos, y además su situación es sensiblemente diferente a la de quienes teorizan sobre el derecho. Los y las litigantes usan reglas y principios que no son objetivos, sino que inevitablemente están cargados de valoraciones; y además los emplean no en nombre de la objetividad, sino en nombre de algo bien personal: sus defendidos y defendidas, y/o sus honorarios. 


\section{- ¿Qué cambios considera urgentes y necesarios para la re- forma de la educación jurídica en el continente?}

Es algo difícil responder en términos generales, pero diría que el primer punto a revisar y a preguntarnos es ¿qué perfil de graduados y graduadas nos interesa alcanzar? Por un lado hay una dimensión muy mercantil del ejercicio litigante, que tiene las formas empresarias o cuenta propistas. Hay otros abogados y abogadas que litigan más en función de compromisos con los grupos subalternos y oprimidos. Por otro lado, hay quienes trabajan en distintas órbitas del Estado y la administración pública, otros y otras que cumplen funciones en el Poder Judicial, y también hay quienes se dedican a la investigación y a la docencia.

El problema es que no se pueden formar todos esos perfiles al mismo tiempo, y entonces hay que tomar una decisión de cuáles perfiles nos interesan más, y cuáles hay que dejar de lado. La decisión sobre el perfil de profesionales a formar es una decisión política, vinculada al modelo de organización política y social, y también relacionada con los modelos universitarios, y por ello tampoco se puede responder en términos genéricos.

Si tomamos el caso de Argentina o el de Bolivia, donde las Universidades públicas no cobrar aranceles a sus estudiantes, y tienen sistemas de ingresos relativamente abiertos, me cuesta encontrar las razones por las cuales privilegiar un perfil de abogado o abogada preparado o preparada para trabajar bajo lógicas empresariales, en lugar de formar profesionales para desempeñarse en la función pública o en la investigación. 
- Recientemente, en Latinoamérica se ha puesto en duda la imparcialidad de la justicia y se ha denunciado su politización. Dichas críticas las hacen tanto agrupaciones de izquierda como de derecha. ¿Cree usted que es necesario reconocer la relevancia de las posiciones ideológicas de los jueces o se debe mantener la pretensión de neutralidad?

En primer lugar, siento alguna incomodidad con estas denuncias de "politización." Básicamente porque se hace de la política un insulto, mientras que yo la concibo como un piropo. En un contexto en el cual la despolitización es funcional a las derechas, creo que desde las izquierdas deberíamos ser un poco más cuidadoso en el empleo de los términos.

Los jueces y las juezas tienen preferencias políticas, e inevitablemente leen las normas y los hechos a la luz de esas preferencias. No porque sean malos jueces o malas juezas, sino porque si tenemos que interpretar el derecho a la propiedad o a la vivienda, necesariamente lo hacemos desde alguna pre comprensión política.

Asimismo, los jueces y las juezas se mueven como actores y actoras políticos/as estratégicos/as, y el Poder Judicial opera como una estructura corporativa que defiende sus intereses. Por su parte, el Poder Judicial recibe presiones del Poder Ejecutivo, del Poder Legislativo, y de grandes corporaciones económicas. Me parece que cuando pensamos los diseños institucionales no podemos hacer como si todo esto no sucediera. En este sentido, si el Poder Judicial está y estará inevitablemente politizado, la tarea no puede ser otra que aquella que desarrollamos con otras instancias de decisión colectiva: democratizarla. 
- Algunas vertientes críticas han optado por cuestionar la legitimidad de las Cortes que tienen un poder contramayoritario en la toma de decisiones, por cuanto pueden ser utilizadas para mantener el status quo de desigualdades e inequidades. No obstante, muchas veces los mismos críticos se han visto perplejos antes las decisiones transformadoras de los Tribunales Constitucionales. En esa encrucijada ¿Cuál es su postura?

Es otra pregunta que a menudo me hago y convivo con esas ambivalencias. En términos generales, mi postura no es muy novedosa al respecto, se acerca a lo que Juan Carlos Bayón denominó en algún trabajo constitucionalismo frágil, y propone un diseño institucional que mantenga el control judicial de constitucionalidad, pero sin que los tribunales constitucionales tengan la última palabra ni la última decisión.A medir por la justicia de los resultados -y no de los procedimientos-, es cierto que en determinadas situaciones las Cortes Constitucionales toman decisiones más progresistas que los Parlamentos, y el caso colombiano ofrece algunos buenos ejemplos.

De todas maneras, pienso que los procesos emancipatorios necesitan fundamentalmente de la participación de las organizaciones sociales y políticas históricamente oprimidas, y no puedo olvidar que durante el gobierno socialista de Salvador Allende, y los primeros años del gobierno del Movimiento al Socialismo en Bolivia, el Poder Judicial fue un potente foco de resistencia a las transformaciones emancipatorias.

En este orden de ideas, creo que si mantenemos el control judicial de constitucionalidad, pero le quitamos al Poder Judicial la última palabra, logramos dos cosas: a- por una parte, evitamos que los y las jueces pongan freno a decisiones políticas adoptadas por gobiernos vinculados con esas organizaciones populares de las que 
creo que dependen los cambios emancipatorios; b- por otra parte, cuando las decisiones jurisdiccionales son más progresistas que las parlamentarias, las organizaciones sociales y políticas siempre tienen el recurso de presión al Parlamento, que debe rendir cuentas a la ciudadanía y a las organizaciones. En la mayoría de los diseños institucionales, el Poder Judicial no le rinde cuentas al pueblo y por ello desconfío en que se guarde la última palabra. De todas maneras, es importante aclarar que este sistema de constitucionalismo frágil, debería articularse con prácticas más participativas en todos los poderes estatales. Hay que quitarle la última palabra a los tribunales, pero también hay que democratizarlos, y hacer más participativas todas las instancias de decisión.

- Se ha señalado que los migrantes están en un limbo jurídico frente a la insuficiencia de los tratados internacionales para la regulación de los desplazados entre países. ¿Qué deben hacer los Estados en América Latina para regular la situación jurídica de migrantes y evitar que se conviertan en mano de obra precarizada o en sujetos que solo son considerados por el sistema jurídico cuando delinquen?

En Nosotros los refugiados, y fundamentalmente en el capítulo noveno de Los orígenes del totalitarismo, Hannah Arendt mostró que la pretendida universalidad de los derechos del hombre no era tal, que eran ineficientes cuando los Estados no reconocían a sus portadores y portadoras como ciudadanos y ciudadanas. Arendt, que entre 1937 y 1951 -fecha de publicación del segundo volumen de Los orígenes del totalitarismo- fue una apátrida, mostró que los derechos del hombre eran en realidad derechos del ciudadano. Mencionaba que los y las apátridas, refugiados y refugiadas, no tenían vulnerado su derecho a la igualdad ante la 
ley porque estaban directamente fuera de la ley. Y si bien algo de eso sucede en Nuestra América, esta situación de exterioridad respecto de la ley se hace más patente en el Norte global, donde las condiciones de ingreso a los Estado y de acceso a la ciudadanía son notablemente más dificultosos.

Los análisis de Arendt fueron retomados, reivindicados y problematizados por autores como Jacques Rancière, Giorgio Agamben, Etienne Balibar, y Slavoj Žižek. Asimismo, han Ilevado a Seyla Benhabib a delinear una teoría de la membresía política a partir de la teoría cosmopolita de la justicia, que incluya el derecho (moral) a tener a tener derechos (jurídicos).

Yo creo que estos análisis son importantes, y aunque no soy un gran admirador de las teorías normativas, me siento interpelado por la propuesta de Benhabib. En términos conceptuales creo que la respuesta al problema es bastante sencilla: hay que desconectar el reconocimiento y la justiciabilidad de los derechos humanos del criterio de nacionalidad y/o ciudadanía.

De todas maneras, en el plano político esta desconexión no es nada sencilla puesto que pone en crisis: por un lado -y aquí me acerco a algunos diagnósticos de Antonio Negri y Michael Hardtun estadío del capitalismo que permite y alienta el flujo de mercancías, datos y finanzas, a la vez que limita el movimiento de personas; por el otro -y aquí me aproximo a Sandro Mezzadra- a la frontera en tanto dispositivo que, entre otras cosas, justamente precariza esa mano de obra que pretende desplazarse. 


\section{- Finalmente ¿Cuáles son, a su juicio, los desafíos del derecho en Latinoamérica?}

Nuestra América está impregnada de múltiples situaciones de opresión y exclusión, que combinan injusticias por redistribución y por reconocimiento. El desafío para resolver estas situaciones es más social y político, que técnico-jurídico. De todas maneras, creo que desde la academia, los tribunales y el litigio, tenemos que desarrollar análisis y prácticas que permitan mostrar cómo el derecho es un agente de legitimación y reproducción de esas injusticias. Pero además, y en vinculación con algo que ya mencioné, si las organizaciones sociales y políticas articulan sus demandas emancipatorias en términos de derechos humanos, tenemos que contribuir a la construcción de una teoría emancipadora de esos derechos. 